\title{
Study of recurrent abdominal pain in children of south Karnataka
}

\author{
Mohan
}

Associate Professor, Department of Pediatrics, Akash Institute of Medical Sciences and Research Centre, Bangalore- 562110, Karnataka, INDIA.

Email: $\underline{\text { mohangm@yahoo.com }}$

\begin{abstract}
Background: RAP is the most common painful health problems in school aged children with various organic causes. It impairs their daily activity and studies as well. Method: 530 school going children (Ratio of male and female was 1:2) were studied as per the Apley's criteria Blood examination LFT, CBC, RBE, Urine stool analysis moreover x-ray USG and CT scan of GIT was carried whenever necessary. In addition to Apley criteria, Rome-II criteria was also considered to diagnose and evaluate the cause of RAP Results: Clinical manifestation were 159(30\%) had 115(21.6\%) had constipation 127(23.9\%) had mesenteric lymphadenopathy, 90(16.9\%) had UTI 30(5.66\%) had hepatomegaly, 9(1.69\%) had splenomegaly. Moreover their BMI and dietary habits were also rule out Conclusion: Majority of the children with RAP had functional GIT diseases, Detail history of patients, hematological, urine, stool, radiological examinations were mandatory to rule out the exact cause. If not cured treated as psycho somatic or emotional/ stress RAP

Key Words: - Emotional, GIT, Apley’s criteria, Rome-II, BMI, pallor
\end{abstract}

\section{*Address for Correspondence:}

Dr Mohan, 26/27-2 1st main, 3rd cross, Amar jyoti layout. Sanjay Nagar, Bangalore-560094, Karnataka, INDIA.

Email: mohangm@yahoo.com

Received Date: 02/12/2019 Revised Date: 13/01/2020 Accepted Date: 05/02/2020

DOI: $\underline{\text { https://doi.org/10.26611/10141522 }}$

This work is licensed under a Creative Commons Attribution-NonCommercial 4.0 International License. $(\mathrm{Cc})$ ) EY-NC

\begin{tabular}{|l|l|}
\hline \multicolumn{2}{|c|}{ Access this article online } \\
\hline Quick Response Code: & Website: \\
& www.medpulse.in \\
& \\
\hline
\end{tabular}

\section{INTRODUCTION}

Abdominal pain is perhaps the most common painful health problem in school going children. J Apley a British pediatrician, studied abdominal pain among the children extensively and observed that, approximately 10 to $15 \%$ of school aged children get recurrent episodes of abdominal pain ${ }^{1}$. He named this symptoms complex as Recurrent abdominal pain,(RAP) syndrome, he also explained that, at least three episodes of abdominal pain, severe enough to affect their activities over longer than three months ${ }^{2}$. Even though the term chronic was also termed when referring to RAP each episode of pain is distinct and separated by periods of well being female children were affected than male children ${ }^{3}$. Abdominal pain is sometimes a sign of life threatening disease. It can also have harmless cause but it can impair the Childs self perception of health and interfere in everyday activities ${ }^{4}$. This affects their study and career. Hence various organic causes have been evaluated by using various techniques like USG, CT scan and blood examination etc.

\section{MATERIAL AND METHODS}

530 school going children of both sexes visiting pediatric OPD Adichanchangiri institute of medical sciences B G Nagar, Nelamangala (Tq) Mandya (dist) Karnataka were studied

Inclusion criteria: Children having Recurrent Abdominal pain (RAP) aged between 6-15 years. Children fulfilling Apleys criteria of RAP were including in the study. 


\begin{tabular}{|c|c|}
\hline Red flags on history & Red flags on physical examination \\
\hline Localized pain away umbilicus & Loss of weight or growing retardation \\
\hline Pain awakening the child at night & Organomegaly \\
\hline Pain associated with changes in bowel habits, dysuria, rash arthritis & Localized abdominal tenderness particularly away the umbilicus \\
\hline Occult bleeding & Joint swelling tenderness or heat \\
\hline Repeated vomiting especially bilious & Pallor rash hernias of the abdominal wall \\
\hline Constitutional symptoms like recurrent fever, loss of appetitive lethargy & \\
\hline
\end{tabular}

Exclusion criteria: Children's having congenital anomalies like volvulus, Mega colon, retroviral diseases children were excluded from the study

Methods: Blood examination CBC, LFT, Urine analysis culture stool examination for cyst ova, parasite, x-ray USG abdomen and lower GIT were carried if necessary. Moreover classification of RAP by symptomatology according Rome-II criteria viz functional dyspepsia, IRBS, (Irritable bowel syndrome) functional abdominal pain, abdominal migraine Aerophasia was also taken into consideration. The duration of study was about three years (from April 1995 to May 1998)

Statistical analysis: Anthropological parameters of BMI, Dietary habits various diseases were classified and grouped with percentage. The ratio of male and female children were 1:2

\section{OBSERVATION AND RESULTS}

Table-1 - Anthropological parameters in RAP childrenIn the study of height $310(58.4 \%)$ were between 147 to $150 \mathrm{~cm} 220(41.5 \%)$ children were between 151 to $157 \mathrm{~cm}$ In the study of weight $340(64.1 \%)$ children were $40 \mathrm{~kg}$ to $44 \mathrm{~kg}, 190$ (35-81) children were between 45 to $48 \mathrm{~kg}$. The BMI study was- 335(63.2\%) children were between 18.2 to 19.2 BMI $195(36.7 \%)$ children were between 19.3 to 20.2 BMI

Table-2- Study of Dietary habits in RAP children was $180(33.9 \%)$ were vegetarian, $152(28.6 \%)$ were Nonvegetarian, 198 (37.3\%) children were both vegetarian and Non-vegetarian,

Table-3- The clinical manifestations of the RAP were $159(30 \%)$ had pallor 115 (21.6\%) had constipation $127(23.9 \%)$ had mesenteric lymphadenopathy, 90 (16.9\%) had UTI, $30(5.66 \%)$ had hepatomegaly 9(1.69) had splenomegaly.

\section{DISCUSSION}

$\mathrm{T}$ he study of RAP in children of south Karnataka- 530 children were studied their anthropological parameters were height-310 (58.4\%) had 147 to $150 \mathrm{~cm}, 220(41.5 \%)$ children had 151 to $157 \mathrm{~cm}$ weight of children was$340(64.1 \%)$ had 40 to $44 \mathrm{~kg}, 190(35.8 \%)$ children had 45 to $48 \mathrm{~kg}$ wt. the BMI study was $335(63.2 \%)$ had 18.2 to 19.2 BMI, 195 (36.7\%) had 19.3 to 20.2 BMI (Table-1). In the study of dietary habits in RAP children- 180 $(33.9 \%)$ were vegetarian $152(28.6 \%)$ were Nonvegetarian, $198(37.3 \%)$ children were both vegetarian and Non-vegetarian (Table-2) The clinical manifestations of the RAP were $-159(30 \%)$ had pallor $115(21.6 \%)$ had constipation 127(23.9\%) had mesenteric lymphadenopathy, 90 (16.9\%) had UTI, 30 $(5.66 \%)$ had hepatomegaly 9(1.69) had splenomegaly.(Table-3) These findings were more or less in agreement with previous studies ${ }^{5,6,7}$. As the abdomen is called as, magic box. Because it consists of many systems like vascular, Uro genital, exocrine and endocrine system. Hence it is challenge to clinical to diagnose RAP without Hematological and radiological support. As RAP does not occur in pre-school children or children below 5 years. Hence RAP might be aggravated by psychological difficulties experienced by children, during school ${ }^{8}$. It was also confirmed that RAP was least observed during summer holidays and many children got symptoms on return to school after vacation ${ }^{9,10}$. It was also reported that, such patients will develop Irritable Bowel syndrome (IRBS) in future, About 25 to 29 histories of RAP patients during school days ${ }^{11}$. Hence apart from medical treatment sympathy, affection, love by the teachers, non-teaching staff towards school going children will have better prognosis in treating RAP

\section{SUMMARY AND CONCLUSION}

The present study of RAP in school going children will be help to pediatrician to treat efficiently the various cause of RAP. As RAP is aggravated during school days psychiatric counseling advice is must because RAP is psycho-somatic rather than organic diseases This research paper was approved by Ethical Committee of AIMS B G Nagar -571432 Mandya (dist) Karnataka 
Table 1: (No of patients 530) Anthropological parameters in RAP children

\begin{tabular}{cccc}
\hline SI No & Parameters & No of patients & Percentage \\
\hline 1 & Height & & \\
& $\begin{array}{l}\text { a- } 147 \text { to } 150 \\
\text { b- } 151 \text { to } 157\end{array}$ & 310 & 58.4 \\
2 & Weight & & 41.5 \\
a- 40 to 44 & 340 & 64.1 \\
b- 45 to 48 & 190 & 35.8 \\
3 & BMI & & \\
& a- 18.2 to 19.2 & 335 & 63.2 \\
& b- 19.3 to 20.2 & 195 & 36.7 \\
\hline
\end{tabular}

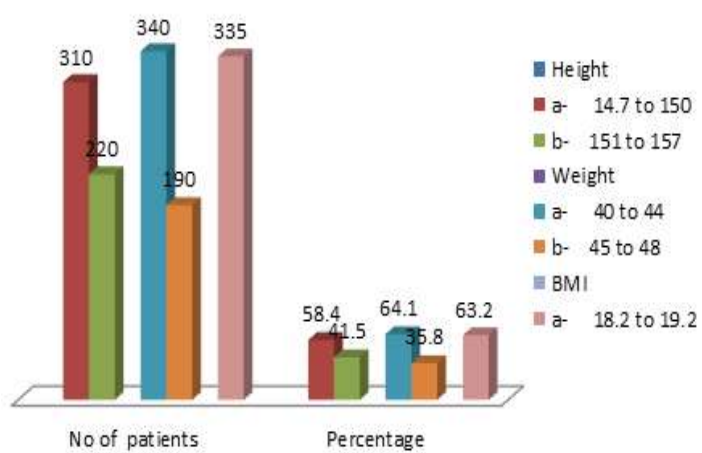

Figure 1: Anthropological parameters in RAP children

Table-2: (No of patients 530) Study of Dietary habits in RAP children

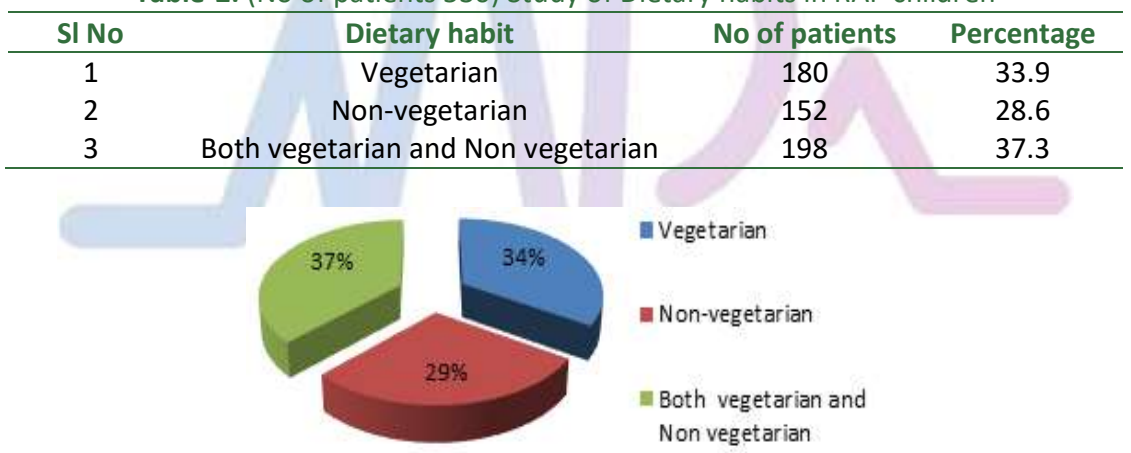

Figure 2: Study of Dietary habits in RAP children

Table 3: (No of patients 530) Clinical Manifestations of RAP in children

\begin{tabular}{cccc}
\hline SI No & Clinical manifestations & No of patients & Percentage \\
\hline 1 & Pallor & 159 & 30 \\
2 & Constipation & 115 & 21.6 \\
3 & Mesenteric lymphadenopathy & 127 & 23.9 \\
4 & Urinary tract Infection (UTI) & 90 & 16.9 \\
5 & Hepatomegaly & 30 & 5.66 \\
6 & Splenomegaly & 09 & 1.69 \\
\hline
\end{tabular}




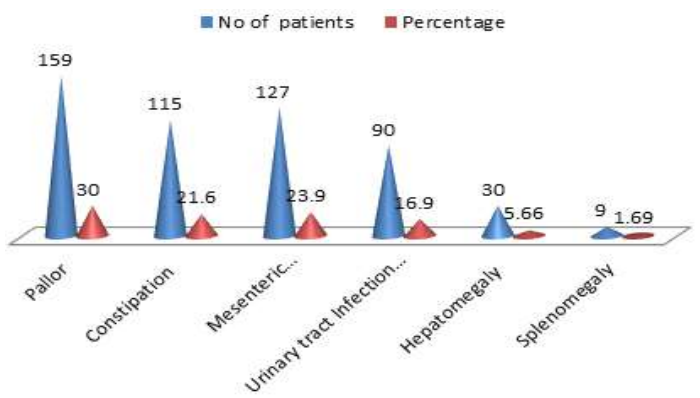

Figure 3: Clinical Manifestations of RAP in children

\section{REFERENCES}

1. Alley's Naish N- Recurrent Abdominal pain A field survey of 1000 school children Arch D,S child 1958,33,165-170

2. Baffler ph, Gross M- Recurrent abdominal pain in childhood Dtsch Arztebl Int.2011,108(17) 205-304

3. Rasul $\mathrm{CH}$, Khan MAD- Recurrent abdominal pain in school children in Bangladesh J. Ceylon coll phys 2000,33,110-114

4. Devnarayana N M, De silva DGH- Recurrent abdominal pain in cohort of Sri Lankan children and adolescents J. Trop paed 2008,54, 178-183

5. Boey cc, Goh KI- Predictors of recurrent abdominal pain among 9 to 15 year old urbon school children in Malaysian. Acta pediatr 2001,90,353-355

6. Dutta S Mehta M- Recurrent abdominal pain in Indian children and its relation with school and family environment Indian paed. 1999. 36, 917-920
7. Hung RC, Palmer L J- Prevalence and Pattern of childhood abdominal pain in an Australian general practice J. paed child health 2000,36,349-353

8. Stordal K Nygarad E A organic abnormalities in recurrent abdominal pain in children Acta padiatri 2001, $90,1-5$

9. O' Donnell B- Out come based on personal experience too small series abdominal pain in children Worcester blacks well scientific publication 1985,106-13

10. Williams N, Jackson D- Incidence of Non specific abdominal pain in children during school term population survey based on discharge diagnose BMJ. 1999,318-455

11. Christensen MF- Mortensen O- Long term prognosis in children with recurrent abdominal pain Arch Dis. child $1975,50,110-114$

\section{Source of Support: None Declared} Conflict of Interest: None Declared

\section{Policy for Articles with Open Access:}

Authors who publish with MedPulse International Journal of Pediatrics (Print ISSN: 2579-0897) (Online ISSN: 2636-4662) agree to the following terms: Authors retain copyright and grant the journal right of first publication with the work simultaneously licensed under a Creative Commons Attribution License that allows others to share the work with an acknowledgement of the work's authorship and initial publication in this journal.

Authors are permitted and encouraged to post links to their work online (e.g., in institutional repositories or on their website) prior to and during the submission process, as it can lead to productive exchanges, as well as earlier and greater citation of published work. 